\title{
Nonlinear Generalized Predictive Control for Air Flow Rate Regulation in the PEM Fuel Cell System
}

\author{
Zhang Haochen ${ }^{1}$, An Aimin ${ }^{1}$ and Xu Tianpeng ${ }^{2}$ \\ College of Electrical and Information Engineering, Lanzhou University of \\ Technology, Lanzhou, 730050, China \\ Science \& Technology Department, Lanzhou University of Technology, \\ Lanzhou, 730050, China \\ lut_zhc@163.com,anaiminll@163.com,119243207@qq.com
}

\begin{abstract}
The particular interest in Proton Exchange Membrane(PEM) fuel cell is based on the possibility to generate the clean and efficiency power. The safety and high operation issues of system are closely related to the control strategy used for fuel and oxidant supply. In PEM fuel cell the oxygen excess ratio expresses the proportion between oxygen supply and consumption and represents a decisive variable for the safety and normal performance. The main control object in this work is to maintain the oxygen excess ratio at the reference value which is obtained by simulation experiments. This work is focused on the design of the nonlinear generalized predictive control strategy manipulating the air flow rate in order to maintain the oxygen excess ratio. This proposed control strategy is based on GPC, and the sequence of control increments, input increment and output constraints solving is introduced to design proposed stair-like GPC method. The experiment results base on simulation platform of PEM FUEL CELL, is built in MATLAB environment, shows the better control effect comparing with fuzzy-PID switching method.
\end{abstract}

Keywords: stair-like GPC, PEM fuel cell, oxygen excess ratio, constrain condition

\section{Introduction}

In recent years, the rapid development of economics has caused environmental problem and energy crisis. Therefore, to explore a new energy source with high efficiency and less pollution is the direction of the human's future. And the hydrogen energy is an important candidate for replacing traditional fuel because of its favorable characteristics. The Proton Exchange Membrane (PEM) fuel cell standing for the hydrogen energy has developed maturely. With its advantage of maneuverable output power, low operation temperature, high current density and quick start, the PEM fuel cell is suitable for the transportation application and distributed generation $[1,2]$.

The PEM fuel cell is chemical engine that converts chemical potential of hydrogen and oxygen into electrical power. The hydrogen normally stored in the tank and is fed through a fast valve to the anode side of fuel cell stack. The air flow is supplied to the cathode side by compressor and can be considered as the control variable of the PEM fuel cell. The main structure of PEM fuel cell is shown in Figure 1. However, insufficient oxygen supply would result in the inlet oxygen flow rate lower than consumption rate which implies a fast stack degradation and low power generation [3]. At the consequence, oxygen has to be supplied sufficiently to fulfill reaction requirements. In several studies controlling the oxygen excess ratio, defined as the rate between oxygen supply and consumption, is proposed to prevent insufficient oxygen supply. The proposed control strategies include feed forward control strategy [4], feedback linearization control [5], adaptive control [6], fuzzy- PID switching control method [7], and model predictive 
control (MPC) $[8,9]$. Nevertheless, most control methods cannot deal with the constraint condition in regulation process. The MPC can solve the constraint problem, but is more complex in algorithm calculation. It is necessary to improve the control strategy to achieve the better control effect.

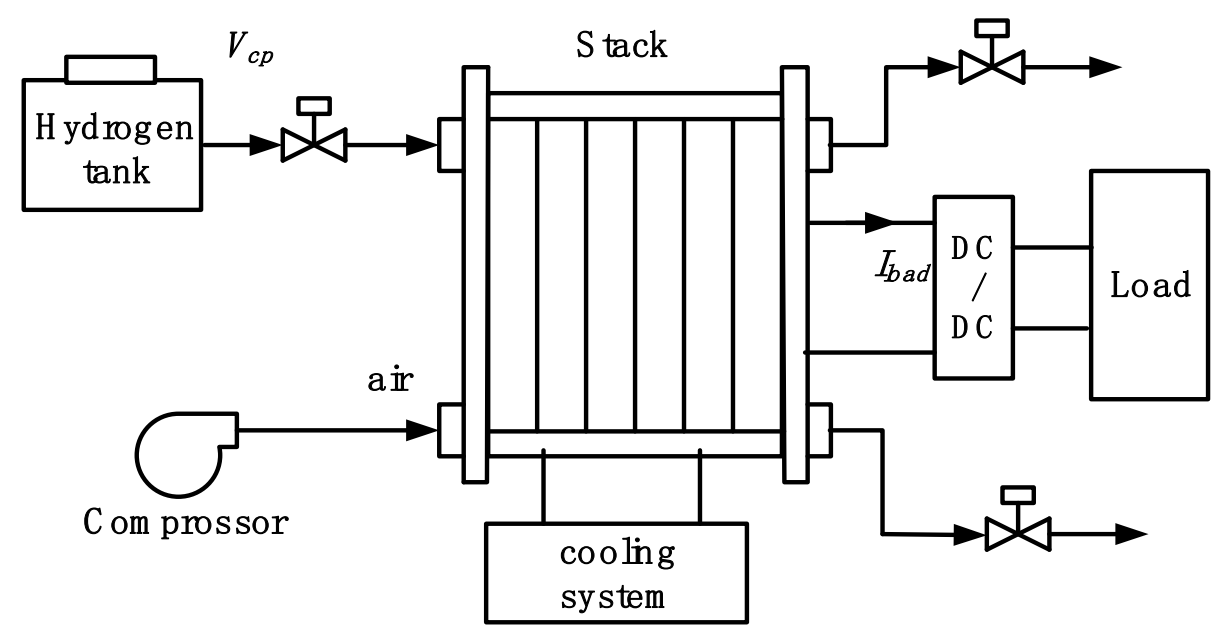

Figure 1. Structures of the PEM Fuel Cell System

The proposed strategy is an improved generalized predictive control with stair-like control increment that is used to regulate the oxygen excess ratio at a desired level under load current changed. The proposed controller is based on a CARIMA model which relates the oxygen excess ratio and compressor voltage. The stair-like sequence of control increment is integrated with the GPC to reduce the optimization calculation of control increment under constraint condition.

The paper is organized as following: Section 2 presents the description of PEM fuel cell system, definition of oxygen excess ratio and control object. Section 3 gives the description of model identification and proposed nonlinear improved GPC algorithm. In section 4, the simulation results obtained proposed control method are shown and compared to the fuzzy-PID method proposed in [7]. And in section 5, the major conclusions are shown.

\section{System Analysis}

This section gives the model description of PEM fuel cell system and mathematical definition of oxygen excess ratio. Then the control object is specified by the simulation analysis.

\subsection{PEM Fuel Cell System}

The work has been performed on a 10KW PEM fuel cell simulation platform. This simulation system is designed in MATLAB environment by mathematical models of PEM fuel cell descried in $[11,12]$. The platform simulates the process of electrochemical reaction in stack, the hydrogen and air supply dynamic in anode and cathode. The stack contains 110 cells, the operation temperature is $343.15 \mathrm{~K}$, the maximum current density is $2.2 \mathrm{~A} / \mathrm{cm}^{2}$, the anode and cathode volume are $5 \mathrm{~L}$ and $10 \mathrm{~L}$ respectively. The simulation platform would be used to replace the actual PEM fuel cell generation system to simulate the dynamic and static characteristics and process of the fuel cell system. The electrochemical reaction in the PEM fuel cell can be expressed as: 


$$
\begin{aligned}
& \text { Anode : } 2 \mathrm{H}_{2} \rightarrow 4 \mathrm{H}^{+}+4 e^{-} \\
& \text {Cathode: } \mathrm{O}_{2}+4 e^{-}+4 \mathrm{H}^{+} \rightarrow 2 \mathrm{H}_{2} \mathrm{O}
\end{aligned}
$$

The output voltage of PEM fuel cell is defined as follows:

$$
V_{\text {stack }}=N\left(E_{\text {Nernst }}-V_{\text {act }}-V_{\text {ohmic }}\right)
$$

Where, $E_{\text {Nernst }}$ is the reversible open circuit voltage of PEM fuel cell stack, $N$ is the number of cell containing in PEM fuel cell, $V_{\text {act }}$ is the activation voltage loss, $V_{\text {ohmic }}$ is the ohmic voltage loss. The description of $E_{\text {Nernst }}, V_{\text {act }}$ and $V_{\text {ohmic }}$ can be seen in [11].

The gas for PEM fuel cell reaction can be supply to anode and cathode side by gas supply system. The gas supply can also be divided in terms of hydrogen and oxygen supply. On the anode, the hydrogen is supplied sufficiently for reaction. And on the cathode, the air is supplied to cathode side by compressor, it contains the oxygen and nitrogen. The vapor is needed in process of electrochemical reaction. The dynamic process of gas supply can be respectively descripted in [12].

\subsection{PEM Fuel Cell System}

The general purpose of this work is to design a suitable control strategy to regulate the oxygen excess ratio, defined as the ratio between oxygen inlet flow $W_{\mathrm{O} 2 \text {,cain }}$ and the oxygen consumption $W_{\mathrm{O} 2 \text {,reacted }}$ in stack. The $\lambda_{\mathrm{O} 2}$ describes the oxygen supply flow rate and is also considered as a performance characteristic of the PEM fuel cell system. Its regulation process is an important issue as $\lambda_{\mathrm{O} 2}$ determines the operation of the PEM fuel cell.

The oxygen excess ratio $\lambda_{\mathrm{O} 2}$ has been defined by Pukrushpan et al. [13] as,

$$
\lambda_{O 2}=\frac{W_{o 2, \text { cain }}}{W_{\text {o2,reacted }}}
$$

The oxygen reacting rate $W_{\mathrm{O} 2 \text {,reacted }}$ is proportional to the stack current $I$ by

$$
W_{o 2, \text { reacted }}=\frac{M_{O 2} N I}{4 F}
$$

with $N$ is the number of cells used in fuel cell stack. The oxygen inlet flow rate $W_{\text {O2,cain }}$ depends on the flow rate of dry air $W_{\mathrm{a}, \text { cain }}$ at the cathode inlet,

$$
W_{o 2, \text { cain }}=0.233 W_{a, \text { cain }}
$$

The mass flow rate of dry air $W_{\mathrm{a}, \text { cain }}$ can be calculated by following,

$$
W_{a, c a i n}=\frac{1}{1+\omega_{c a, i n}} W_{c a, i n}
$$

With the humidity ratio $\omega_{\text {ca,in }}$ can be defined as,

$$
\omega_{c a, i n}=\frac{M_{V}}{M_{a, c a i n}} \frac{P_{\text {sat }}}{P_{a, \text { cain }}}
$$

$M_{\mathrm{v}}$ and $M_{\mathrm{a} \text {,cain }}$ are the molar mass of vapor and air at cathode inlet, and $M_{\mathrm{v}}$ is $18 \mathrm{~g} / \mathrm{mol}$, $M_{\mathrm{a} \text {,cain }}$ is $29 \mathrm{~g} / \mathrm{mol}$. The vapor pressure $P_{\text {sat }}[12]$ and dry air pressure $P_{\mathrm{a}, \text { cain }}$ are described as following,

$$
\begin{aligned}
& P_{\text {sat }}=10^{\left(2.95 \times 10^{-2} T-9.18 \times 10^{-5} T^{2}+1.44 \times 10^{-7} T^{3}-2.18\right)} \\
& P_{\text {a,cain }}=P_{\text {cain }}-P_{\text {sat }}
\end{aligned}
$$

The cathode inlet pressure $P_{\text {cain }}$ can be measured by a pressure sensor installed at the compressor outlet. Therefore, the measuring process can be expressed by a simple mathematical model which is the function of air flow rate and stack current [14]. 


$$
P_{\text {cain }}=1.013 \times 10^{5}+21.21 W_{\text {cain }}-48.05 I_{s t}
$$

The air flow rate $W_{\text {cain }}$ depends on the compressor motor voltage $V_{\text {com }}$ and the process can be expressed by the following transfer function form [14].

$$
\frac{W_{\text {cain }}(s)}{V_{\text {com }}(s)}=\frac{-0.128 s^{3}+5.44 s^{2}+1.71 \times 10^{4} s+3.03 \times 10^{6}}{s^{4}+167 s^{3}+39700 s^{2}+2.28 \times 10^{6} s+8.26 \times 10^{7}}
$$

As already mentioned, the objective of control method in this paper is to regulate the oxygen excess ratio at the suitable value. And the oxygen inlet flow rate $W_{02 \text {,cain }}$ and consumption rate $W_{\mathrm{O} 2 \text {,reacted }}$ influence the oxygen excess ratio. It is clearly that the oxygen consumption rate $W_{\mathrm{O} \text {,reacted }}$ depends only on the stack current $I_{\mathrm{st}}$. As the consequence, the oxygen excess ratio $\lambda_{\mathrm{O} 2}$ has to be regulated by the oxygen inlet flow rate $W_{\mathrm{O} 2 \text {,cain }}$.

\subsection{Control Object of Oxygen Excess Ratio}

As already mentioned above, the regulation of oxygen excess ratio $\lambda_{\mathrm{O} 2}$ is an important issue in PEM fuel cell control for both safety and operation. The effect of load current changed, regarded as the main disturbance of system, influence the oxygen consumption rate $W_{\mathrm{O} 2 \text {,reacted. }}$ If oxygen inlet rate $W_{\mathrm{O} \text {,cain }}$ could not adjust to load current changed, the oxygen excess rate $\lambda_{\mathrm{O} 2}$ would not maintain at the suitable level, as is shown in Figure 2.

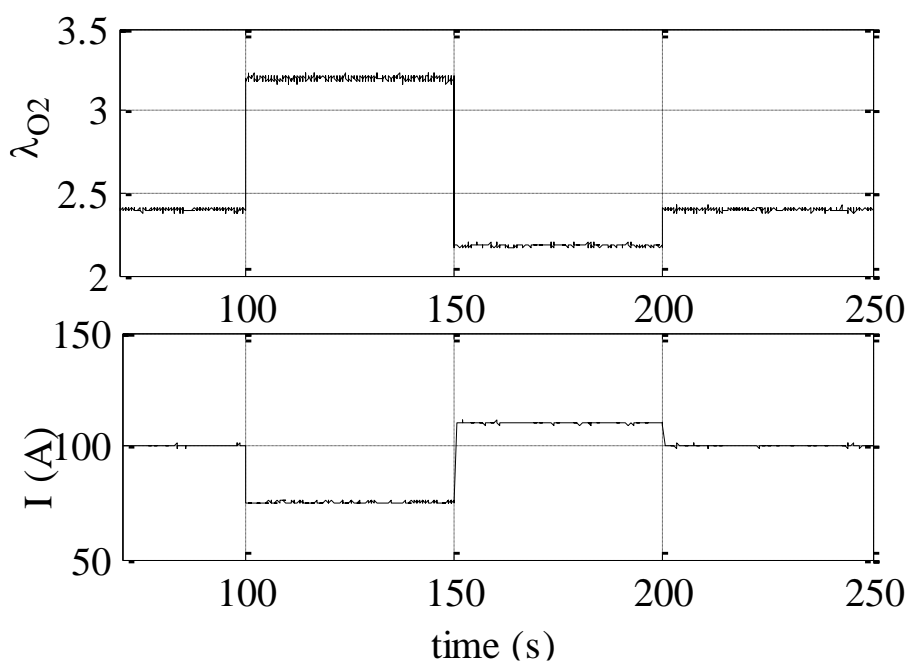

Figure 2. Load Current Changed Influences the Oxygen Excess Ratio: Air Compressor Voltage is $8 \mathrm{~V}$.

To avoid the oxygen starvation phenomenon, the oxygen excess ratio has to satisfy condition as $\lambda_{\mathrm{O} 2}>1$. During the operation process of PEM fuel cell, the output power of system for a certain load current increases along with the oxygen excess ratio until reaching a maximum point. Finally, based on simulation experiment data, the control set value of $\lambda_{\mathrm{O} 2 \text {,ref }}=2.6$ has been chosen for safety margin and high system output power.

\section{Control Strategy Design for Oxygen Excess Ratio}

This section presents the design process of the control strategy which is used to regulate the oxygen excess ratio at the setting point by compressor voltage. As solving the optimization problem complicates the use of prediction model in the GPC framework, it is necessary to get a prediction model relating the input $V_{\text {com }}$ to the output $\lambda_{\mathrm{O} 2}$ by system identification. 


\subsection{Prediction Model Identification}

As already mentioned in Section 2.2, the oxygen excess ratio $\lambda_{\mathrm{O} 2}$ can be defined as a simple function in (6), consisting of the air flow rate $W_{\text {cain, }}$ stack current/ load current $I$, pressure $P_{\text {cain, }}$, temperature $T$, humidity ratio $\omega_{\text {ca,in, }}$, and so on.

$$
\lambda_{O 2}=f\left(W_{\text {cain }}, I, P_{\text {cain }}, T, \omega_{\text {cain }}\right)
$$

The air flow rate $W_{\text {cain }}$ depends on the compressor voltage $V_{\text {com }}$, temperature $T$ is considered as the constant. Stack current/ load current $I$ considered as a disturbance. In this work, the CARIMA model, suitable for sequence of stair-like control increment used in GPC, is used to relate the input $V_{\text {com }}$ to the output $\lambda_{\mathrm{O} 2}$ as the prediction model:

$$
A\left(z^{-1}\right) y(k)=z^{-d} B\left(z^{-1}\right) \Delta u(k)+C\left(z^{-1}\right) \xi(k)
$$

Where $y(k)$ is the output (oxygen excess ratio $\lambda_{\mathrm{O} 2}$ ), $\Delta u(k)$ is the increment (compressor voltage increment $\left.\Delta V_{\text {com }}(k)\right)$ as,

$$
\Delta V_{\text {com }}(k)=V_{\text {com }}(k)-V_{\text {com }}(k-1)
$$

$A\left(z^{-1}\right), B\left(z^{-1}\right)$ and $C\left(z^{-1}\right)$ are polynomials in backward shift operator $z^{-1}$ :

$$
\begin{aligned}
& A\left(z^{-1}\right)=1+a_{1,1} z^{-1}+a_{1,2} z^{-2}+\cdots+a_{1, n a} z^{-n a} \\
& B\left(z^{-1}\right)=b_{1,0}+b_{1,1} z^{-1}+b_{1,2} z^{-2}+\cdots+b_{1, n b} z^{-n b} \\
& C\left(z^{-1}\right)=1+c_{1,1} z^{-1}+c_{1,2} z^{-2}+\cdots+c_{1, n c} z^{-n c}
\end{aligned}
$$

In this work, the second order CARIMA model is used, and $d=1, C\left(z^{-1}\right)=1$. The forgetting factor least square algorithm described as following, is introduced to identify the parameters in $A\left(z^{-1}\right)$ and $B\left(z^{-1}\right)$.

$$
\begin{aligned}
& \boldsymbol{\theta}(k)=\boldsymbol{\theta}(k-1)+\boldsymbol{K}(k)\left[y(k)-\boldsymbol{\varphi}^{T}(k) \boldsymbol{\theta}(k-1)\right] \\
& \boldsymbol{K}(k)=\frac{\boldsymbol{P}(k-1) \boldsymbol{\varphi}(k)}{\lambda+\boldsymbol{\varphi}^{T}(k) \boldsymbol{P}(k-1) \boldsymbol{\varphi}(k)} \\
& \boldsymbol{P}(k)=\frac{1}{\lambda}\left[\boldsymbol{I}-\boldsymbol{K}(k) \boldsymbol{\varphi}^{T}(k)\right] \boldsymbol{P}(k-1)
\end{aligned}
$$

The $\lambda$ is forgetting factor with $\lambda=0.98$. The parameters can be obtained in $\theta(k)$. The input signals for identification combined with white noise signals.

A comparison between the oxygen excess ratio $\lambda_{\mathrm{O} 2}$ based on simulation platform and the output of the identified model can be seen in Figure 3 for some operation points. The load current is also introduced in identification process as the disturbance. The results show that the identified model approximates the dynamics behavior of the system based on simulation platform. 


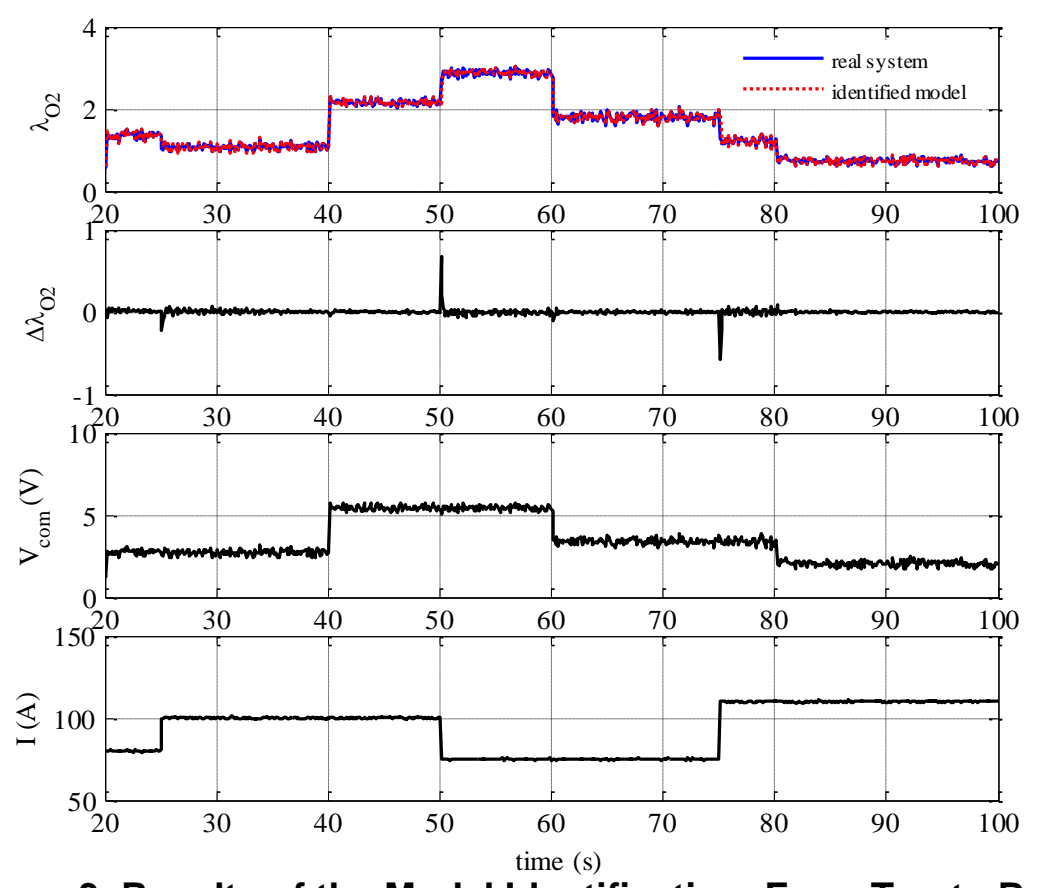

Figure 3. Results of the Model Identification. From Top to Bottom:

Oxygen Excess Ratio $\Lambda_{\mathrm{o} 2}$ and Output of the Identified Model, Input Signals

(Compressor Voltage $V_{\text {com }}$ ) and Bottom: Load Current I

\subsection{Nonlinear Generalized Predictive Control}

The identified CARIMA model can be used in the generalized predictive control strategy with parameter adaptation to load current changes. The predicted future output is calculated by Diophantine equation in generalized predictive control, and calculation is more complex. The improved nonlinear GPC proposed in this paper is based on the method for formulating future output method, and then the stair-like sequence of control increments and solving constraint condition are introduced for regulating the oxygen excess ratio.

The future output can be described as

$$
\boldsymbol{Y}^{*}=\boldsymbol{Y}_{m}+\boldsymbol{H} \Delta \boldsymbol{U}
$$

Where

$$
\begin{aligned}
& \boldsymbol{Y}^{*}=\left[y^{*}(k+d), y^{*}(k+d+1), \cdots, y^{*}\left(k+N_{p}\right)\right]^{\mathrm{T}} \\
& \boldsymbol{Y}_{m}=\left[y_{m}(k+d), y_{m}(k+d+1), \cdots, y_{m}\left(k+N_{p}\right)\right]^{\mathrm{T}} \\
& \Delta \boldsymbol{U}=\left[\Delta u(k), \Delta u(k+1), \cdots, \Delta u\left(k+N_{p}-d\right)\right]^{\mathrm{T}} \\
& \boldsymbol{H}=\left[\begin{array}{cccc}
b_{1,0} & 0 & \cdots & 0 \\
b_{2,0} & b_{1,0} & \cdots & 0 \\
\vdots & \vdots & \vdots \\
b_{N-d+1,0} & b_{N-d, 0} & b_{1,0}
\end{array}\right]
\end{aligned}
$$

$N_{\mathrm{p}}$ is the maximum predictive step. $y_{\mathrm{m}}(k+i)$ can be calculated by control input and output in the past. 


$$
\begin{gathered}
y_{m}(k+j)=-\sum_{i=1}^{n a} a_{1, i} y_{m}(k+j-i)+\sum_{i=1}^{n b} b_{1, i} \Delta u(k+j-d-i)+ \\
\sum_{i=1}^{n c} c_{1, i} \xi(k+j-i), j=1,2, \cdots, N_{p}
\end{gathered}
$$

$b_{\mathrm{j}, 0}$ in $\boldsymbol{H}$ is defined as,

$$
\begin{aligned}
& b_{j, 0}=b_{1, j-1}-\sum_{i=1}^{j_{1}} a_{1, i} b_{j-i, 0}, j=2,3, \cdots, N-d+1 \\
& j_{1}=\min \{j-1, n a\}
\end{aligned}
$$

The optimization problem in proposed generalized predictive control algorithm is considered:

$$
\begin{aligned}
& \Delta \boldsymbol{u}^{*}=\arg \min _{\Delta u} J \\
& \text { s.t. } \Delta \boldsymbol{u}_{\text {min }} \leq \Delta \boldsymbol{u} \leq \Delta \boldsymbol{u}_{\text {max }}
\end{aligned}
$$

$J$ is the quadratic cost function, and can be defined generally as

$$
\boldsymbol{J}=\left(\boldsymbol{Y}-\boldsymbol{Y}_{r}\right)^{T}\left(\boldsymbol{Y}-\boldsymbol{Y}_{r}\right)+\Delta \boldsymbol{U}^{T} \boldsymbol{\Gamma} \Delta \boldsymbol{U}
$$

Where $\boldsymbol{Y}_{\mathrm{r}}$ denotes the reference vector and $\boldsymbol{\Gamma}$ represents the weighting factor matrix with factor $\gamma$ for the control increments which allows the tuning of the controller towards a more aggressive or a smoother behavior,

$\boldsymbol{\Gamma}=\operatorname{diag}(\gamma)$

Then considering the control increments $\Delta u(k+j), \Delta u(k+j-1)$ and the stair factor $\beta$, the stair-like control increments can be defined as

$$
\Delta u(k+j)=\beta \Delta u(k+j-1), j=1,2, \cdots, N_{p}-1
$$

and $\Delta \boldsymbol{U}$ is

$$
\begin{aligned}
\Delta \boldsymbol{U} & =\left[\Delta u(k), \beta \Delta u(k+1), \cdots, \beta^{N_{p}-1} \Delta u\left(k+N_{p}-d\right)\right]^{\mathrm{T}} \\
& =\Delta u(k) \boldsymbol{\beta}
\end{aligned}
$$

where $\boldsymbol{\beta}=\left[1, \beta, \beta^{2}, \ldots, \beta^{\mathrm{Np}-1}\right]^{\mathrm{T}}$

The future output can be described as

$$
\boldsymbol{Y}^{*}=\boldsymbol{Y}_{m}+\Delta u(k) \boldsymbol{H} \boldsymbol{\beta}=\boldsymbol{Y}_{m}+\Delta u(k) \boldsymbol{G}
$$

Using the definition (21) in (18), the cost function can be expressed directly as

$$
J=\left(\boldsymbol{Y}_{m}+\Delta u(k) \boldsymbol{G}-\boldsymbol{Y}_{r}\right)^{T}\left(\boldsymbol{Y}_{m}+\Delta u(k) \boldsymbol{G}-\boldsymbol{Y}_{r}\right)+\Delta u^{2}(k) \boldsymbol{\beta}^{T} \boldsymbol{\Gamma} \boldsymbol{\beta}
$$

It is clearly that $\boldsymbol{Y}_{\mathrm{m}}, \boldsymbol{Y}_{\mathrm{r}}$ and $\boldsymbol{G}$ is the column vector, and cost function can be described as,

$$
\begin{aligned}
J= & \Delta u^{2}(k)\left(\boldsymbol{G}^{\mathrm{T}} \boldsymbol{G}+\boldsymbol{\beta}^{\mathrm{T}} \boldsymbol{\Gamma} \boldsymbol{\beta}\right)+\Delta u(k)\left(\boldsymbol{Y}_{m}^{\mathrm{T}} \boldsymbol{G}+\boldsymbol{G}^{\mathrm{T}} \boldsymbol{Y}_{m}-\boldsymbol{G}^{\mathrm{T}} \boldsymbol{Y}_{r}-\boldsymbol{Y}_{r}^{\mathrm{T}} \boldsymbol{G}\right) \\
& +\left(\boldsymbol{Y}_{m}-\boldsymbol{Y}_{r}\right)^{\mathrm{T}}\left(\boldsymbol{Y}_{m}-\boldsymbol{Y}_{r}\right)
\end{aligned}
$$

The $\Delta u(k)$ can be calculated through solving the optimization problem with constraints. And the new control action $u(k)$ is defined as,

$$
u(k)=u(k-1)+\Delta u(k)
$$

Finally, the proposed constrained nonlinear generalized predictive control strategy can be used to regulate the oxygen excess ratio $\lambda_{\mathrm{O} 2}$ maintaining at the setting point $\lambda_{\mathrm{O} 2 \text {,ref }}$ with load current changes. The control structure to regulate oxygen excess ratio is shown in Figure 4. The SGPC in Figure 4, means the JGPC combined with stair-like sequence of control increments, is the control strategy proposed in this work.

Considering the constraint of output signals as $y_{\min } \leq y$, the condition can be presented as the constraint of control increments by (19). 


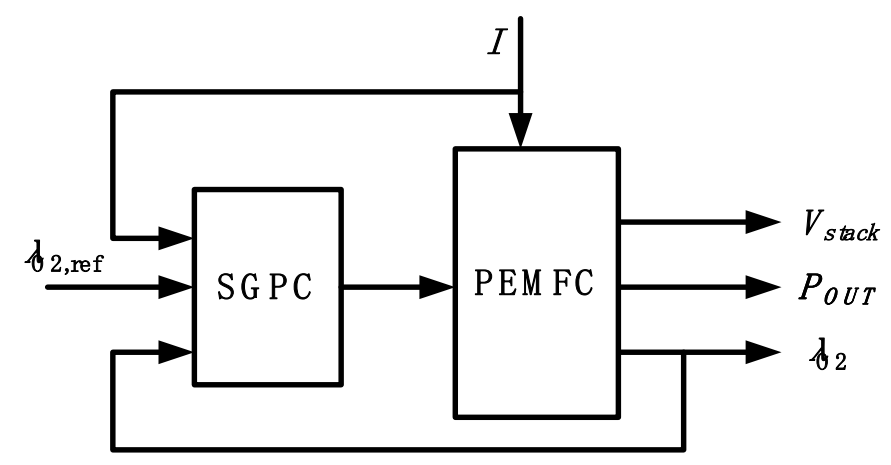

Figure 4. Proposed SGPC Structure to Regulate the Oxygen Excess Ratio $\Lambda_{02}$ to the Desired Value $\lambda_{02, \text { ref. }}$

\section{System Analysis}

The proposed SGPC was implemented on the PEM fuel cell simulation platform mentioned in section 2.1. The sampling time was set to $10 \mathrm{~ms}$. For the prediction horizon values of $N_{\mathrm{p}}=8$ was chosen, the weighting factor and stair factor used in the control strategy were respectively set to the value of $\gamma=1$ and $\beta=0.2$. The control constraints both in control signal increments and output were considered:

$$
\begin{aligned}
& 1 \leq \lambda_{o 2}(k) \\
& -1 \mathrm{~V} \leq \Delta u(k)
\end{aligned}
$$

The upper constraint of $\lambda_{\mathrm{O} 2}$ in the control action was chosen for safety reasons to prevent oxygen starvation phenomenon. Future more, the limitation of control signals need to be considered. During the simulation experiment (see Figure 5), the load current I varies from $75 \mathrm{~A}$ to $110 \mathrm{~A}$ was applied to the system. The simulation results show that the control strategy regulates the oxygen excess ratio $\lambda_{02}$ to the desired value in the presence of stepwise changes in the load current.

The simulation experiment was repeated with the fuzzy-PID switching control strategy in [7] in order to compare the simulation with proposed SGPC algorithm. And a detailed comparison of the reaction of both control strategies to changes in the load current $I$ is given in Figure 6. It can be observed that the SGPC has the better dynamic response than fuzzy-PID switching method in oxygen excess ratio regulation. The PEM fuel cell system output power is the output power of stack minus the consumption power of compressor. It can be seen that the system output power adjusting with SGPC higher than fuzzy-PID switching control, which means less power of compressor is consumed with SGPC strategy. In order to allow a better comparison of the two controllers the sum of square errors (SSE) for the results carried out with the SGPC and fuzzy-PID switching is given in Table 1. The comparison of the SSEs shows a slightly better performance of SGPC. 


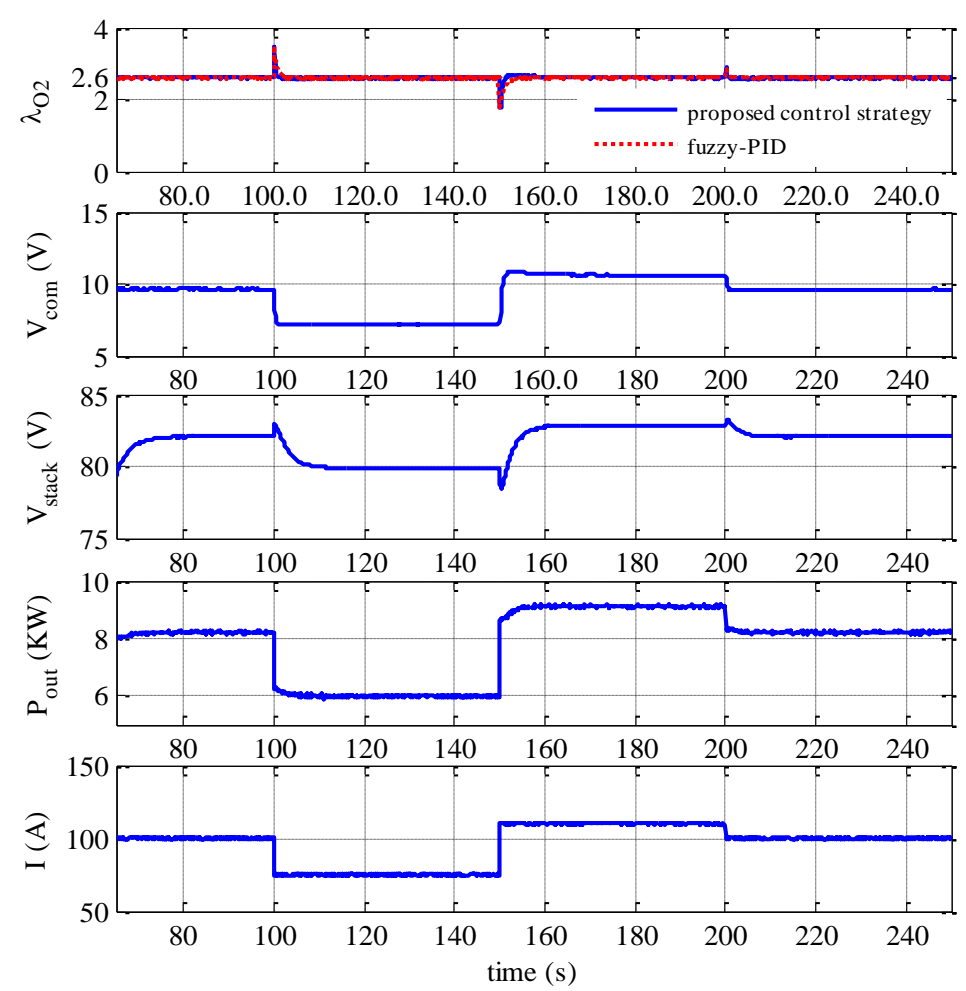

Figure 5. Simulation Experimental Results of the Oxygen Excess Ratio $\Lambda_{02}$ Controlled by the Proposed SGPC with Step Changes In Load Current $I$. From Top To Bottom: Oxygen Excess Ratio $\Lambda_{02}$, Compressor Voltage $V_{\text {com, }}$, Stack Voltage $V_{\text {stack, }}$, Output Power of Fuel Cell $P_{\text {out }}$ and Load Current $I$

The presented results show that the proposed SGPC can be used to regulate the oxygen excess ratio $\lambda_{\mathrm{O} 2}$ to desire value in presence of stepwise changes in the load current $I$.

Table 1. Comparison of the SSE for Simulation Results Shown in Figure 6 for SGPC and Fuzzy-PID Switching Method

\begin{tabular}{l|l|l}
\hline \hline Index & SGPC & Fuzzy-PID switching \\
\hline SSE, $\mathrm{t}=[90,110] \mathrm{s}$ & 1.3913 & 1.9648 \\
\hline $\mathrm{SSE}, \mathrm{t}=[140,160] \mathrm{s}$ & 2.4839 & 2.6784 \\
\hline SSE, $\mathrm{t}=[190,210] \mathrm{s}$ & 0.1999 & 0.2460 \\
\hline \hline
\end{tabular}



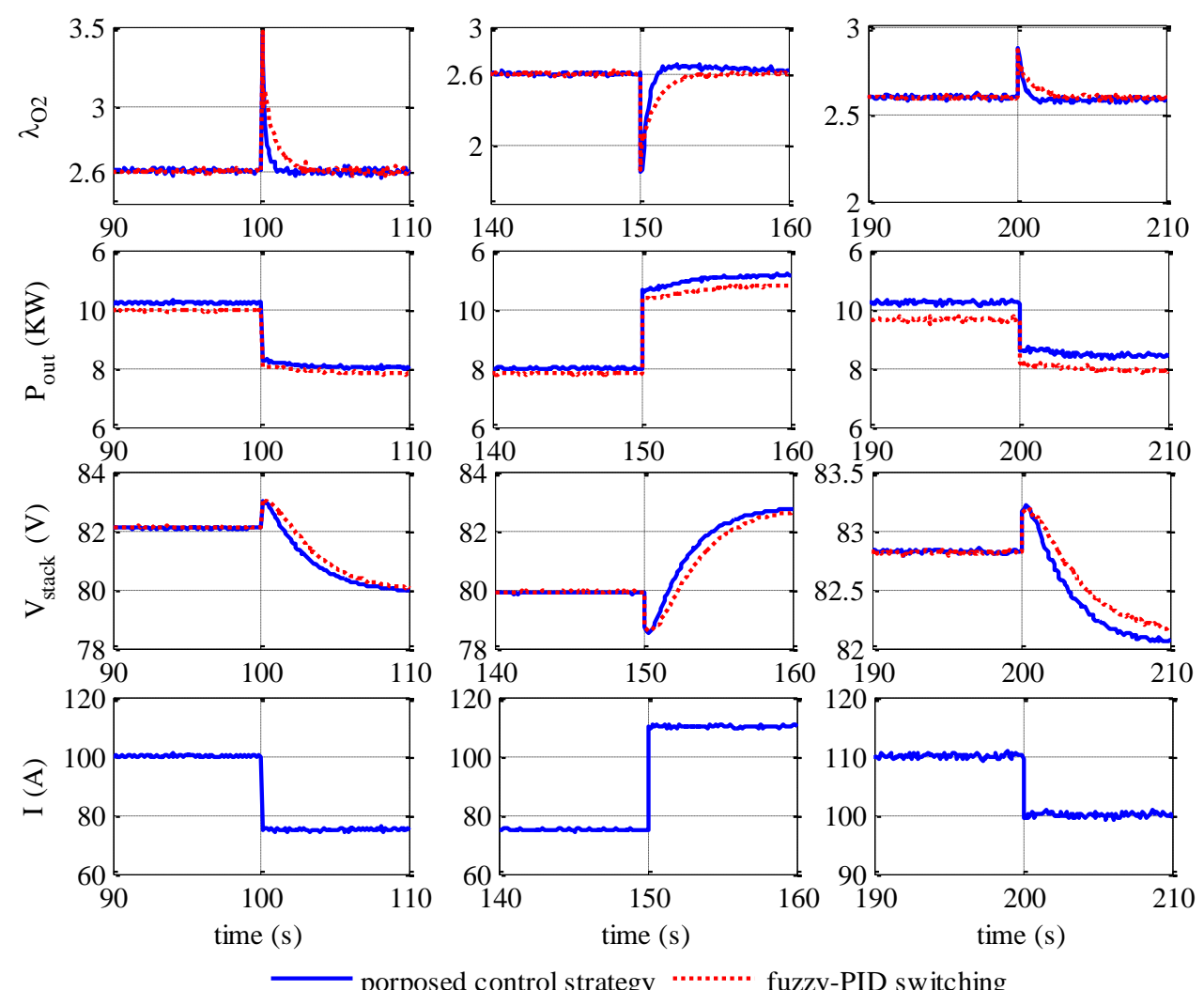

Figure 6. Simulation Experimental Comparison of Oxygen Excess Ratio $\Lambda_{02}$ Controlled by Proposed SGPC and Fuzzy-PID Switching Method With Step Changes in Load Current I. From Top To Bottom: Oxygen Excess Ratio $\Lambda_{02}$, Output Power of Fuel Cell $\boldsymbol{P}_{\text {out }}$, Stack Voltage $\boldsymbol{V}_{\text {stack }}$ and Load Current $I$

\section{Conclusions}

In this work the development of a generalized predictive control strategy for the oxygen excess ratio of the PEM fuel cell has been presented. The control of the oxygen excess ratio is carried out regulating the compressor voltage and manipulating the air flow rate at the cathode inlet. The proposed control strategy is based on JGPC, the sequence of control increments and constrain solving is introduced to simplify the calculation process. Then, the SGPC under input increments and output constraints was implemented on the PEM fuel cell simulation platform built in MATLAB environment, and experimentally tested on the platform. The simulation results showed that the proposed control strategy can be used for the constant set point for the oxygen excess ratio. Comparing with fuzzyPID switching method, the proposed SGPC has the better control effect in oxygen excess ratio, stack voltage and output power of the fuel cell system.

\section{Acknowledgements}

This work is supported by the Gansu Province Foundation of Youth Science and Technology under Grant No. 145RJYA313, Nation Natural Science Foundation of China under Grant No. 61563032. 


\section{References}

[1] A. G. Stefanopoulou and K. W. Suh, "Mechatronics in fuel cell system", Control Engineering Practice, vol.15, no.3, (2007), pp.277-289.

[2] C. Daia, W. Chena, Z. Chenga, Q. Lia, Z. Jianga and J. Jiab, "Seeker optimization algorithm for global optimization, A case study on optimal modelling of proton exchange membrane fuel cell (PEM fuel cell)", International Journal of Electrical Power \& Energy Systems, vol.33, no.3, (2011), pp.369-376.

[3] N. Yousfi-Steinera, Ph. Moçotéguy, D. Candussoc and D. Hisselb, "A review on polymer electrolyte membrane fuel cell catalyst degradation and starvation issues: Causes, consequences and diagnostic for mitigation", Journal of Power Sources, vol.194, no.1, (2009), pp.130-145.

[4] J. Pukrushpana, A. Stefanopouloub, S. Varigondac, J. Ebornc and C. Haugstetter, "Control-oriented model of fuel processor for hydrogen generation in fuel cell applications", Control Engineering Practice, vol.14, no.3, (2006), pp.277-293.

[5] W. Ki Na and B. Gou, "Feedback linearization based nonlinear control for PEM fuel cells", IEEE Trans. on Energy Convers, vol.23, no.1, (2008), pp.179-190.

[6] J. Zhang, G. Liu, W. Yu and M. Ouyang, "Adaptive control of the airflow of a PEM fuel cell system", Journal of Power Sources, vol.179, no.2, (2009), pp.649-659.

[7] X. Hao, H. Zhang, A. An, X. Liu and L. Chen, "Fuzzy Double Model Control for Air Supply on a PEM Fuel Cell System", Communications in Computer and Information Science, vol.355, (2013), pp.392400.

[8] J. K. Gruber, M. Doll and C. Bordons, "Design and experimental validation of a constrained MPC for the air feed of a fuel cell”, Control Engineering Practice, vol.17, no.8, (2009), pp.874-885.

[9] A. Arce, A. J. Real, C. Bordons and D. R. Ramirez, "Real-Time Implementation of a Constrained MPC for Efficient Airflow Control in a PEM Fuel Cell”, IEEE Transactions on Industrial Electronics, vol.57, no.6, , (2010)pp.1892-1905.

[10] Y. Jin and X. Gu, "Improved Generalized Predictive Control", Information and Control, (1990), no.3, pp.8-14.

[11] S. V. Puranik, A. Keyhani and F. Khorrami, "State space modeling of proton exchange membrane fuel cell”, IEEE Transactions on Energy Conversion, vol.25, no.3, (2010), pp.804-813.

[12] P.-C. Chen, "The dynamics analysis and controller design for the PEM fuel cell under gas flow rate constraints", International Journal of Hydrogen Energy, vol.36, no.4, (2011), pp.3110-3122.

[13] J. T. Pukrushpan, A. G. Stefanopoulou and H. Peng, "Control of Fuel Cell Power Systems: Principles, Modeling, Analysis and Feedback Design”, Springer press, London, (2004).

[14] H. Peng and A. G. Stefanopoulou, "Control oriented modeling and analysis for automotive fuel cell systems”, Journal of Dynamic Systems, Measurement, and Control, vol.126, (2004), pp.14-25.

\section{Authors}
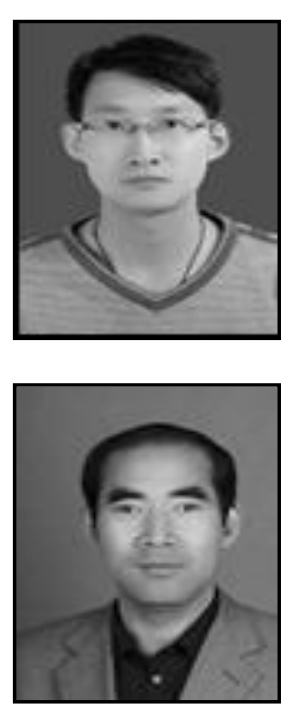

Zhang Haochen, he was born in China on 28 November 1987. He obtained received the M.Eng. degree in control science and engineering from the Northeastern University, Shenyang, China, in 2009, the M.Sc. degree in Control Theory and Engineering from the Lanzhou University of Technology, Lanzhou, China, in 2010. He is currently working at the College of Electrical and Information Engineering. His current research interests are focused on control theory and application in fuel cell and predictive control.

An Aimin, he was born in China on 1972. He obtained received the Doctor of Philosophy in Engineering in Theory and Engineering from the Lanzhou University of Technology, Lanzhou, China, in 2010. He is currently working at the College of Electrical and Information Engineering. His current research interests are focused on control theory and application in predictive control. 
International Journal of Control and Automation

Vol. 9, No. 10 (2016) 